\title{
Survival among children with portal vein thrombosis and end-stage liver disease
}

\begin{abstract}
Al-Holou S, Mathur AK, Ranney D, Kubus J, Englesbe MJ. Survival among children with portal vein thrombosis and end-stage liver disease. Pediatr Transplantation 2010: 14: 132-137. @ 2009 John Wiley \& Sons A/S.

Abstract: Occlusive PVT concurrent with chronic liver disease is a common clinical entity among pediatric patients referred for transplantation. The natural history of PVT is unknown. Our aim was to determine, using a retrospective cohort design, if children under $13 \mathrm{yr}$ with chronic liver disease and concomitant PVT have an increased mortality risk prior to and after transplantation. A total of 203 patients were included in the study. Nearly $10 \%$ of the population had PVT $(\mathrm{n}=19) ; 63.2 \%$ of PVT patients $(5.9 \%$ of total cohort) underwent liver transplantation $(\mathrm{n}=12)$. PVT patients tended to be younger than non-PVT patients at evaluation $(1.94 \pm 3.51$ vs. $3.79 \pm 4.11, \mathrm{p}=0.059)$. Clinical and demographic factors were similar between the two groups. Regarding survival, four PVT patients died, of which two had undergone transplantation. Kaplan-Meier analyses indicated that PVT and non-PVT patients had similar survival from the time of evaluation, on the waiting list, and after transplant. Although limited by sample size, our study suggests that a diagnosis of PVT does not increase the mortality risk for children waiting for a liver transplant. Further study is needed to discern variations in mortality risk that may occur in the pediatric chronic liver disease population with PVT.
\end{abstract}

\section{Shaza Al-Holou, Amit K. Mathur, David Ranney, James Kubus and Michael J. Englesbe}

Division of Transplantation, Department of Surgery, University of Michigan, Ann Arbor, MI, USA

\author{
Key words: portal vein thrombosis - end-stage live \\ disease - pediatric liver transplantation - pediatric \\ end-stage liver disease - mortality \\ Michael J. Englesbe, MD, University of Michigan \\ Health System, 2926 Taubman Center, 1500 E. \\ Medical Center Drive, Ann Arbor, Ml 48109-0331, \\ USA \\ Tel.: +734-936-9623 \\ Fax: +734-763-3187 \\ E-mail: englesbe@med.umich.edu \\ Accepted for publication 12 February 2009
}

Occlusive PVT is a relatively common complication of chronic liver disease in both adults and children (1-4). The pathogenesis of PVT is linked to local factors in the portal vein related to increased resistance to portal venous flow in cirrhosis, resulting in venous stasis that contributes to thrombophilia. Systemic factors, including acquired or inherited coagulation abnormalities, dovetail with the local vascular changes, resulting in varying degrees of vessel thrombosis $(1,5,6)$. Patients with PVT may present with acute hepatic decompensation in the setting of chronic liver disease but, more commonly, PVT is noted as an incidental finding upon radiographic evaluation $(1,7,8)$.

The natural history of patients with chronic liver disease complicated by PVT is largely unknown (7). PVT causes significant morbidity in children,

Abbreviations: MR, magnetic resonance; PELD, pediatric end-stage liver disease; PV, portal vein; PVT, portal vein thrombosis; SMV, superior mesenteric vein. including intractable ascites, variceal bleeding, hypersplenism, and encephalopathy. These complications can be particularly difficult to manage in children, and associated mortality is reportedly high $(3,6,8-11)$. In the context of pediatric patients, this fact is particularly troubling. Beyond its associated morbidity, PVT can also complicate the liver transplant operation, but advanced surgical techniques have made this manageable $(4,9$, 12-15). Expedited access to transplantation through allocation policy maneuvers may be warranted if children with chronic liver disease complicated by PVT have significantly inferior survival on the liver transplant waiting list.

Our hypothesis is that in a pediatric population with chronic liver disease, those with a comorbid diagnosis of PVT have a significantly increased risk of death vs. their non-PVT counterparts prior to transplant. In this study, we aimed to address this hypothesis by reviewing pediatric patients with chronic liver disease who were evaluated for transplant at our center. 
Survival among children with portal vein thrombosis and end-stage liver disease

\section{Methods}

All pediatric patients with chronic liver disease, under $13 \mathrm{yr}$ old, and not previously transplanted that were evaluated in the multi-disciplinary liver transplant clinic at our center between January 1, 1995 and March 30, 2007 were included in the study cohort $(n=203)$. PELD scores at the time of evaluation and transplant were calculated for each patient using primary data from our center's transplant database.

PVT was defined as complete thrombotic occlusion of the main PV. PVT was diagnosed on the basis of liver ultrasound, and all cases were confirmed in one of three ways: liver magnetic resonance imaging study, percutaneous mesenteric venogram, or intraoperative identification at the time of liver transplantation. Patients with mesenteric venous occlusion, such as in the right PV, left PV, splenic vein, or superior mesenteric vein were not considered to have PVT unless main PV occlusion was present.

\section{Analysis}

The initial analytic approach included a patient-level analysis employing the presence of PVT as the main exposure variable. The primary outcome variable was mortality. Demographic variables including age, race, and diagnosis were compared between children with and without PVT. Clinical variables including mean follow-up, rate of waiting list registration, rate of liver transplantation, and unadjusted survival at end of follow-up were compared between the two groups. These univariate analyses were completed using the chi-square method for categorical variables and an unpaired $t$-test for continuous variables.

The Kaplan-Meier method was used to calculate mortality rates. Statistical differences were established using the log-rank test. Kaplan-Meier survival curves were created from the time of patient evaluation to death, time of transplantation to death, and overall survival. Patient survival was censored at death or at the end of follow-up. No patients were lost to follow-up. The Institutional Review Board at the University of Michigan approved this study. SPSS V15.0 (Chicago, IL, USA) was used to complete the analysis. Statistical significance was defined at the level of $\mathrm{p}=0.05$.

\section{Results}

Patient demographics and clinical management

A total of 203 patients were included in the study. Nineteen patients had PVT $(9.4 \%)$, and 184 patients had no evidence of PVT (90.6\%). Patients with PVT tended to be female, but otherwise patients across the entire cohort had similar descriptive statistics regardless of PVT status, as seen in Table 1. Race and cause of liver disease were not significantly different between the groups, nor were PELD scores at evaluation and transplantation. PVT patients tended to be younger at the time of evaluation vs. non-PVT patients, and this difference was significant at transplantation (age at transplant, PVT vs. non-PVT, $2.31 \pm 3.37 \mathrm{yr}$ vs. $5.38 \pm$ $4.54 \mathrm{yr}, \mathrm{p}=0.027)$. Biliary atresia was the
Table 1. Characteristics of 203 children evaluated for a liver transplant at the University of Michigan with and without complete occlusion of the portal vein

\begin{tabular}{|c|c|c|c|}
\hline & $\begin{array}{l}\text { No PVT } \\
(\mathrm{n}=184)\end{array}$ & $\begin{array}{l}\text { PVT } \\
(n=19)\end{array}$ & $\mathrm{p}$-Value \\
\hline Gender (n, males) (\%) & $101(54.9)$ & $7(36.8)$ & 0.153 \\
\hline \multicolumn{4}{|l|}{ Race (n) $(\%)$} \\
\hline Caucasian & $111(60.3)$ & $13(68.4)$ & \multirow[t]{3}{*}{0.665} \\
\hline Non-Caucasian & $57(31.0)$ & $4(21.1)$ & \\
\hline Unknown & $16(8.7)$ & $2(10.5)$ & \\
\hline \multicolumn{4}{|l|}{ Cause of liver disease (n) (\%) } \\
\hline Alagille's syndrome & $10(5.4)$ & $0(0)$ & \multirow{9}{*}{0.099} \\
\hline Autoimmune & $14(7.6)$ & $0(0)$ & \\
\hline Biliary atresia & $76(41.3)$ & $15(78.9)$ & \\
\hline Cryptogenic & $19(10.3)$ & $3(15.8)$ & \\
\hline Hepatitis, neonatal & $8(4.3)$ & $0(0)$ & \\
\hline Hepatoblastoma & $6(3.3)$ & $0(0)$ & \\
\hline Metabolic & $16(8.7)$ & $0(0)$ & \\
\hline Short gut & $5(2.7)$ & $0(0)$ & \\
\hline Other & $30(16.3)$ & $1(5.3)$ & \\
\hline Age at evaluation (yr) & $3.79 \pm 4.11$ & $1.94 \pm 3.51$ & 0.059 \\
\hline Age at transplant (yr) & $5.38 \pm 4.54$ & $2.31 \pm 3.37$ & 0.027 \\
\hline PELD at evaluation & $6.91 \pm 11.20$ & $1.80 \pm 7.47$ & 0.158 \\
\hline PELD at transplant & $11.82 \pm 8.11$ & $12.75 \pm 7.23$ & 0.824 \\
\hline \multicolumn{4}{|l|}{ Type of donor (n) (\%) } \\
\hline Deceased & $70(92.1)$ & $11(91.7)$ & \multirow[t]{2}{*}{1.000} \\
\hline Living related & $6(7.9)$ & $1(8.3)$ & \\
\hline \multicolumn{4}{|l|}{ Cause of death (n) (\%) } \\
\hline Cardiac arrest & $2(5.0)$ & $0(0)$ & \multirow[t]{6}{*}{0.943} \\
\hline Hemorrhage & $1(2.5)$ & $0(0)$ & \\
\hline Malignancy & $1(2.5)$ & $0(0)$ & \\
\hline Multiple system organ failure & $4(10.0)$ & $1(25.0)$ & \\
\hline Respiratory failure & $1(2.5)$ & $0(0)$ & \\
\hline Unknown & 31 (77.5) & $3(75.0)$ & \\
\hline
\end{tabular}

primary diagnosis for more than $75 \%$ of PVT patients $(\mathrm{n}=15)$. One patient with PVT and biliary atresia had splenosis syndrome; $10.5 \%$ $(\mathrm{n}=2)$ of PVT patients had documented inherited hypercoagulability, and one PVT patient was chronically anticoagulated for hypercoagulability without an identified coagulation mutation.

Table 2 further details the demographics of the patients who did and did not matriculate to the liver transplant waiting list; $56.2 \%$ of patients evaluated were placed on the waiting list $(\mathrm{n}=114)$. Patients with PVT were significantly more likely to be listed compared to patients without PVT $(p=0.050)$. Patients who were placed on the wait-list had a significantly higher PELD score at the time of evaluation $(9.6 \pm 9.8$ vs. $3.0 \pm 11.5, \mathrm{p}<0.001)$. Fig. 1 displays the trajectory of the 203 patients who were evaluated for liver transplant during the study interval. A total of 88 children underwent liver transplantation during the study period. Of the patients with PVT, $12(63.2 \%)$ underwent liver transplantation, accounting for $80 \%$ of PVT patients placed on the waiting list $(n=15)$. One child with biliary atresia who underwent liver transplanta- 
Al-Holou et al.

Table 2. Clinical and demographic trends of 203 children with end-stage liver disease by liver transplant waiting list status

\begin{tabular}{llll}
\hline & $\begin{array}{l}\text { Wait-listed } \\
(\mathrm{n}=114)\end{array}$ & $\begin{array}{l}\text { Not wait-listed } \\
(\mathrm{n}=89)\end{array}$ & p-Value \\
\hline PVT (n) (\%) & $15(13.2)$ & $4(4.5)$ & 0.05 \\
Age at evaluation (yr) & $3.94 \pm 4.41$ & $3.21 \pm 3.61$ & 0.206 \\
Gender (n, males) (\%) & $56(49.1)$ & $52(58.4)$ & 0.204 \\
Race (n) (\%) & & & \\
Caucasian & $68(59.6)$ & $56(62.9)$ & 0.364 \\
$\quad$ Non-Caucasian & $38(33.3)$ & $23(25.8)$ & \\
Unknown & $8(7.0)$ & $10(11.2)$ & \\
Cause of liver disease (n) (\%) & & & \\
$\quad$ Alagille's syndrome & $6(5.3)$ & $4(4.5)$ & 0.0000 \\
Autoimmune & $10(8.8)$ & $4(4.5)$ & \\
Billiary atresia & $64(56.1)$ & $26(29.2)$ & \\
Cryptogenic & $5(4.4)$ & $16(18.0)$ & \\
$\quad$ Hepatitis, neonatal & $2(1.8)$ & $6(6.7)$ & \\
Hepatoblastoma & $2(1.8)$ & $4(4.5)$ & \\
$\quad$ Metabolic & $12(10.5)$ & $4(4.5)$ & \\
Short gut & $0(0)$ & $5(5.6)$ & \\
Other & $13(11.4)$ & $20(22.5)$ & \\
PELD at evaluation & $9.58 \pm 9.74$ & $2.99 \pm 11.52$ & 0.001 \\
Mortality (n, deaths) (\%) & $27(23.7)$ & $17(19.1)$ & 0.494 \\
\hline
\end{tabular}

tion had portal vein atresia without splenosis. Waiting-list outcomes in the PVT cohort also included one death and two remaining alive at the end of follow-up. Of the PVT patients who were not wait-listed, three were alive at the end of follow-up, and one had died.

Table 3 refers to all patients with PVT, their diagnoses, transplantation statuses, and times to death if applicable. Two PVT patients died after transplant, one within 30 days of transplant from multiple organ system failure and the other approximately seven months post-transplant from pneumonia.

Survival from time of initial evaluation, wait-listing, and following a liver transplant

Kaplan-Meier analyses of patient survival, stratified by the presence or absence of PVT, are demonstrated in Fig. 2. The first curve depicts similar survival rates from the time of evaluation across the entire study population (PVT vs. nonPVT, $p=0.606)$. PVT and non-PVT patients on the waiting list had similar survival rates (PVT vs. non-PVT, $p=0.548)$. Post-transplant survival was relatively uniform between the groups (PVT vs. non-PVT, $\mathrm{p}=0.911$ ).

\section{Conclusions}

This study is a single institution series describing our 12-yr experience in the evaluation and liver transplantation of children with the diagnosis of occlusive PVT. The overall prevalence of PVT in children evaluated for transplantation was $9.4 \%$. Children with PVT tended to be female, were younger at the time of their evaluation, and were transplanted at a younger age than their counterparts without PVT. We hypothesized that children with chronic liver disease and PVT had an increased risk of death prior to transplantation. When comparing the PVT and non-PVT

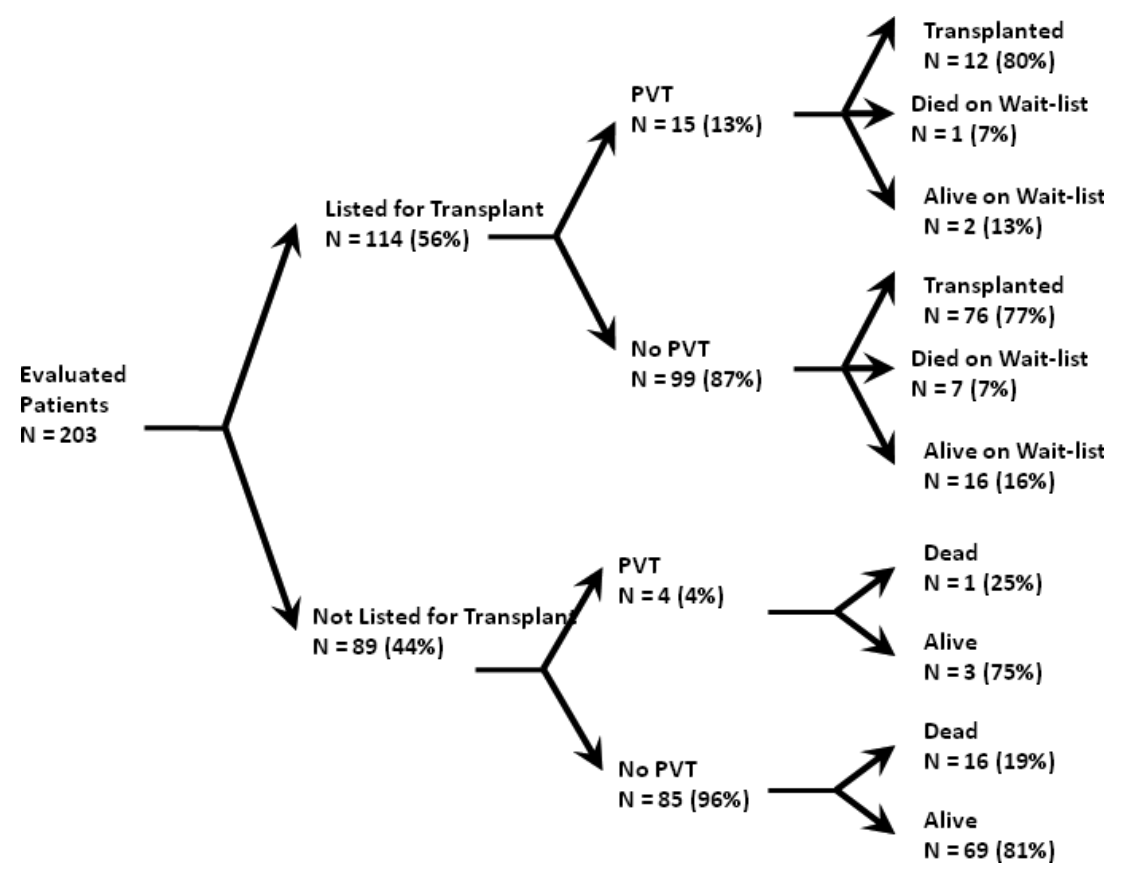

Fig. 1. Clinical trajectory of 203 pediatric patients from liver transplant evaluation. 
Survival among children with portal vein thrombosis and end-stage liver disease

Table 3. Diagnoses, transplant status, and mortality of 19 patients with occlusive portal vein thrombosis following transplant evaluation

\begin{tabular}{|c|c|c|c|c|c|}
\hline \multirow[b]{2}{*}{ Patient } & \multirow{2}{*}{$\begin{array}{l}\text { Cause of } \\
\text { liver disease }\end{array}$} & \multirow{2}{*}{$\begin{array}{l}\text { Age at } \\
\text { transplant (yr) }\end{array}$} & \multicolumn{3}{|c|}{ Death } \\
\hline & & & $\mathrm{Y} / \mathrm{N}$ & Cause & Post-transplant lifespan (days) \\
\hline 1 & Biliary atresia & 1.5 & Y & Multiple organ system failure & 29 \\
\hline 2 & Biliary atresia & 0.9 & $\mathrm{~N}$ & & \\
\hline 3 & Biliary atresia & 0.5 & $\mathrm{~N}$ & & \\
\hline 4 & Biliary atresia & 0.4 & $\mathrm{~N}$ & & \\
\hline 5 & Biliary atresia & 12.8 & $\mathrm{~N}$ & & \\
\hline 6 & Biliary atresia & 0.6 & $\mathrm{~N}$ & & \\
\hline 7 & Hemangioendothelioma & 1.0 & $\mathrm{~N}$ & & \\
\hline 8 & Biliary atresia & 2.0 & Y & Pneumonia & 206 \\
\hline 9 & Biliary atresia & 2.5 & $\mathrm{~N}$ & & \\
\hline 10 & Biliary atresia & 1.6 & $\mathrm{~N}$ & & \\
\hline 11 & Biliary atresia & 2.2 & $\mathrm{~N}$ & & \\
\hline 12 & Biliary atresia & 1.7 & $\mathrm{~N}$ & & \\
\hline 13 & Biliary atresia & $\mathrm{N} / \mathrm{A}$ & $\mathrm{N}$ & & \\
\hline 14 & Biliary atresia & $\mathrm{N} / \mathrm{A}$ & Y & Pulmonary embolism & \\
\hline 15 & Cryptogenic & $\mathrm{N} / \mathrm{A}$ & $\mathrm{N}$ & & \\
\hline 16 & Biliary atresia & $\mathrm{N} / \mathrm{A}$ & $\mathrm{N}$ & & \\
\hline 17 & Biliary atresia & $\mathrm{N} / \mathrm{A}$ & $\mathrm{N}$ & & \\
\hline 18 & Cryptogenic & $\mathrm{N} / \mathrm{A}$ & $\mathrm{N}$ & & \\
\hline 19 & Cryptogenic & $\mathrm{N} / \mathrm{A}$ & Y & Multiple organ system failure & \\
\hline
\end{tabular}


Fig. 2. Kaplan-Meier survival curves for children with and without occlusive portal vein thrombosis from evaluation, waiting list registration, and after liver transplantation.

populations, overall, waiting list, and post-transplant mortality were similar between the groups. The hypothetical increased mortality risk was not supported by our analysis. Policies facilitating early transplantation, possibly at low PELD scores, for patients who have chronic liver 
disease complicated by PVT may not be appropriate.

Portal vein thrombosis is found in $8-14 \%$ of the cirrhotic population and can portend lifethreatening complications $(6-9,16)$. It is associated with thrombophilic disorders, including the prothrombin 20210 mutation, and the resistance to portal venous flow that occurs in the pathophysiology of cirrhosis (1), and usually warrants anticoagulation (3). Our series had $15.8 \%$ overall rate of hypercoagulability in the PVT cohort, which reflects that seen elsewhere (1). PVT has been associated with worse post-transplant outcome in the adult liver transplantation population in some series (17). Several papers have described technical success of the liver transplant operation in patients with PVT using a variety of techniques including endvenectomy, venous bypass, and cavoportal transposition, but not without increased risk to the recipient $(4,9,15)$. Transplantation is possible in the vast majority of patients with portal vein thrombosis, though frequently these operations are technically challenging. Long-segment chronic thrombosis of the SMV does not necessarily preclude liver transplantation if inflow can be obtained through the portal vein via either the splenic vein or generous mesenteric collaterals. If both the splenic and SMV are chronically occluded and no candidate collaterals are noted, the child should be referred for evaluation for multi-visceral transplantation.

Several limitations are notable in this study. Selection bias in creation of the cohort is a significant limitation, due to the retrospective nature of the study. Patients who were thought to be too sick for transplantation at the time of evaluation may not have undergone a Doppler ultrasound to detect PVT, leading to a false reduction in the overall prevalence. Furthermore, MR contrast portography may have more sensitivity in detecting fully occlusive PVT (18). We focused on younger children and excluded adolescent patients from the analysis, and thus no conclusions can be made about older children with PVT. Due to the low prevalence of PVT in our small cohort, the study may lack sufficient statistical power to detect differences in survival. Patient heterogeneity within the PVT cohort may also limit conclusions, due to differences in risk due to hypercoagulability and anatomic anomalies such as portal vein atresia. Further studies may include creation of a multivariate model to determine specific covariates associated with waiting list and post-transplant survival, using registry-based data or a multi-center case series. Based on the current available data as well as our current study, children with end-stage liver dis- ease and PVT should undergo liver transplantation if they are otherwise reasonable candidates.

Our initial hypothesis has implications for public policy in the era of PELD score-directed liver allocation. Given the scarcity of pediatric liver donors, an increased risk of PELD-adjusted waiting list mortality with PVT would suggest the need for an adjustment in allocation, potentially via an exception point scheme. Our data intimate that specific policies granting systematic exceptions to patients with chronic liver disease complicated by PVT are not necessary. Patients with PVT likely receive more pretransplant care for management of the complications of portal hypertension, but they do not seem to have excess pretransplant mortality. Certainly, within the context of limitations of this manuscript, additional study is needed on PVT in pediatric patients with chronic liver disease. PVT status is reported in national transplant registries, and our intention is to conduct a more comprehensive evaluation using these data.

\section{Financial support}

AKM is supported by a NIH/NRSA T32 training grant. MJE is supported by a grant from the American Surgical Association Foundation.

\section{References}

1. Amitrano L, Guardascione MA, Brancaccio V, et al. Risk factors and clinical presentation of portal vein thrombosis in patients with liver cirrhosis. J Hepatol 2004: 40: 736-741.

2. Denninger MH, Chait Y, Casadevall N, et al. Cause of portal or hepatic venous thrombosis in adults: The role of multiple concurrent factors. Hepatology 2000: 31: 587-591.

3. Soganrd KK, Astrup LB, Vilstrup H, Gronbaek H. Portal vein thrombosis; risk factors, clinical presentation and treatment. BMC Gastroenterol 2007: 7: 34.

4. Molmenti EP, Roodhouse TW, Molmenti H, et al. Thrombendvenectomy for organized portal vein thrombosis at the time of liver transplantation. Ann Surg 2002: 235: 292-296.

5. VAlla DC, Condat B. Portal vein thrombosis in adults: Pathophysiology, pathogenesis and management. J Hepatol 2000: 32: 865-871.

6. Janssen HL, Wijnhoud A, HaAgsma EB, et al. Extrahepatic portal vein thrombosis: Aetiology and determinants of survival. Gut 2001: 49: 720-724.

7. Ogren M, Bergqvist D, Buorck M, Acosta S, Eriksson H, Sternby NH. Portal vein thrombosis: Prevalence, patient characteristics and lifetime risk: A population study based on 23,796 consecutive autopsies. World J Gastroenterol 2006: 12: 2115-2119.

8. Orloff MJ, Orloff MS, Orloff SL, Girard B. Portal vein thrombosis in cirrhosis with variceal hemorrhage. J Gastrointest Surg 1997: 1: 123-130.

9. Egawa H, Tanaka K, Kasahara $M$, et al. Single center experience of 39 patients with preoperative portal vein thrombosis among 404 adult living donor liver transplantations. Liver Transpl 2006: 12: 1512-1518.

10. Gerbes AL. The patient with refractory ascites. Best Pract Res Clin Gastroenterol 2007: 21: 551-560. 
Survival among children with portal vein thrombosis and end-stage liver disease

11. Schettino GC, Fagundes ED, Roquete ML, Ferreira AR, Penna FJ. Portal vein thrombosis in children and adolescents. J Pediatr (Rio J) 2006: 82: 171-178.

12. Fuchs J, Warmann S, Kardorff R, et al. Mesenterico-left portal vein bypass in children with congenital extrahepatic portal vein thrombosis: A unique curative approach. J Pediatr Gastroenterol Nutr 2003: 36: 213-216.

13. Gehrke I, John P, Blundell J, Pearson L, Williams A, de VILLE DE GoYet J. Meso-portal bypass in children with portal vein thrombosis: Rapid increase of the intrahepatic portal venous flow after direct portal hepatic reperfusion. J Pediatr Surg 2003: 38: 1137-1140.

14. Mack CL, Zelko FA, Lokar J, et al. Surgically restoring portal blood flow to the liver in children with primary extrahepatic portal vein thrombosis improves fluid neurocognitive ability. Pediatrics 2006: 117: e405-412.
15. Selvaggi G, Weppler D, Nishida $\mathrm{S}$, et al. Ten-year experience in porto-caval hemitransposition for liver transplantation in the presence of portal vein thrombosis. Am J Transplant 2007: 7: 454-460

16. Francoz C, Belghiti J, Vilgrain V, et al. Splanchnic vein thrombosis in candidates for liver transplantation: Usefulness of screening and anticoagulation. Gut 2005: 54: 691-697.

17. Englesbe MJA-HS, Muhammad W, Ranney D, Kubus J, Pelletier SJ. Are Patients With Portal Vein Thrombosis HighRisk Liver Transplant Candidates? ASTS 8th Annual State of the Art Winter Symposium, Marco Island, FL, 2008.

18. Cakmak O, Elmas N, Tamsel $S$, et al. Role of contrast-enhanced 3D magnetic resonance portography in evaluating portal venous system compared with color Doppler ultrasonography. Abdom Imaging 2008: 33: 65-71. 